Characterization and

Qualification of New TATB and Kel-F 800 for LX-17

D. Mark Hoffman, Sabrina C. DePiero

February 21, 2007 
This document was prepared as an account of work sponsored by an agency of the United States Government. Neither the United States Government nor the University of California nor any of their employees, makes any warranty, express or implied, or assumes any legal liability or responsibility for the accuracy, completeness, or usefulness of any information, apparatus, product, or process disclosed, or represents that its use would not infringe privately owned rights. Reference herein to any specific commercial product, process, or service by trade name, trademark, manufacturer, or otherwise, does not necessarily constitute or imply its endorsement, recommendation, or favoring by the United States Government or the University of California. The views and opinions of authors expressed herein do not necessarily state or reflect those of the United States Government or the University of California, and shall not be used for advertising or product endorsement purposes.

This work was performed under the auspices of the U.S. Department of Energy by University of California, Lawrence Livermore National Laboratory under Contract W-7405-Eng-48. 


\title{
Characterization and Qualification of new TATB and Kel-F 800 for LX-17
}

\author{
Mark Hoffman and Sabrina Depiero \\ L-282, High Explosives Application Facility \\ Lawrence Livermore National Laboratory \\ Phone: 925-422 7759; e-mail: hoffman2@llnl.gov
}

\section{Background}

Currently LLNL has no Kel-F 800 or dry-aminated TATB reserves for formulation. Although both materials are soon to be commercially available, their synthesis processes have changed and the explosive must be re-evaluated.

In 2000 3M phased out the uses of perfluorooctanoyl (C8) derivatives due to environmental persistence and bioaccumulation issues. A C8 derivative was used as an emulsifier for making FK-800. In 2001 FK-800 was scheduled to be discontinued and the last FK-800 run was made in early 2002. LANL ordered 2M\$ worth of Kel-F 800 for reserves and Pantex purchased several hundred pounds to satisfy mock needs. After four years, 3M has decided to introduce a Kel-F 800-like polymer based on a new emulsifier using the same chlorotrifluoroethylene and vinylidene fluoride monomers and emulsion polymerization process. They have produced 3 batches and claim the "new" FK-800 is indistinguishable from the "old" Kel-F 800 in any of their testing parameters. In JuneJuly 2006 3M scaled up a batch of about 800 pounds and have test quantities available. We have samples of the new FK-800 for evaluation. [1,2]

Neither wet nor dry-aminated TATB has been synthesized in the US in any significant quantity since about 1985 and significant quantities of LX-17-1 has not been formulated since about 1990.[3] Over the last few years as part of a DOD MANTECH, Thiokol [4] and Holston Army Ammunition Plant (HAAP) [5] have produced moderate quantities of TATB ( $\sim 5 \mathrm{~kg}$ batches) with plans to scale up for DOD applications. Thiokol TATB is polycrystalline with an average particle size of about $40 \mu \mathrm{m}$ (similar to WA TATB) but HAAP TATB is only 5-6 $\mu \mathrm{m}$ (similar to ultrafine). We have obtained small quantities of these materials for evaluation. [6]

\section{Scope of work:}

The project would (1) compare new FK-800 with old Kel-F 800 and KF-800 lots currently available at LLNL, (2) compare and characterize new TATB with old TATB, (3) formulate new FK-800 with wet-aminated TATB and new TATBs in according to HAAP slurry coating procedure into LX-17-2, and (4) evaluate the mechanical and detonation performance characteristics of this insensitive high explosive (IHE). Priorities will be to prove that these new materials can be formulated, pressed to density and machined; and that they contain no impurities which might cause compatibility issues. Since 3M [1, 2], LANL [7], Pantex [8] and AWE [9, 10] are currently evaluating the new FK-800, we plan to share data rather than repeating their work. Our effort is described briefly below. 
Task 1. Evaluation of newer characterization methods to identify structural variations between old and new Kel-F 800 including: Rheological and mechanical properties, copolymer content, degree of crystallinity, and interfacial interactions with TATB.

Task 2. Evaluate TATBs using scattering techniques to replace sieving operations called out in the specification [12] for particle size distribution measurements. Use SEM and OM for morphological differences between the old and new explosives. Evaluate the compaction characteristics of new TATB.

Task 3. Formulation of new LX-17-2 (with new FK-800 and/or new TATB)

Task 4. Evaluate mechanical and performance properties of LX-17-2. At a minimum, compressive strength, dynamic mechanical behavior and a 2" cylinder shot should be performed and compared with existing data for LX-17-1.

\section{Results and Discussion:}

Task 1. Characterization of Kel-F 800.

A. Dynamic Mechanical Properties including the storage and loss modulus (G' and G”) of 10 lots of Kel F 800 were measured over the temperature range from -150 to $70^{\circ} \mathrm{C}$ at five frequencies between 0.1 and $10 \mathrm{~Hz}$ in $3^{\circ} \mathrm{C}$ increments at $0.01 \%$ strain. A typical, 1 $\mathrm{Hz}$ trace is shown in Figure 1. Three methods have been used to estimate the glass transition temperature of the Kel-F 800 polymer. (1) $T_{g}\left(G^{\prime}\right)$ - the intersection of the slopes of the low and intermediate drop off in of the shear storage modulus (blue in Figure 1) reflects the onset of the glass transition at about $26.3^{\circ} \mathrm{C}$ and $0.33 \mathrm{GPa}$. (2) The peak in the loss modulus (green squares) occurs approximately $20 \%$ of the way through the glass transition at $28.7^{\circ} \mathrm{C}$. (3) The peak in $\tan (\delta)$ (red diamonds) occurs at toward the middle of the glass transition at $38.2^{\circ} \mathrm{C}$. The $\beta$-relaxation, which occurs as a peak near $80^{\circ} \mathrm{C}$ in the loss modulus, is not shown in the Figure. The $\beta$-relaxation and the glass transition temperature measured from peaks in the loss modulus and tangent delta varied with the measurement frequency. Measurements of the glass transition temperature at constant frequency based on the peak in the loss tangent and in G” for all 10 lots are shown in Figure 2. Arrhenius fits to all the data are shown as blue dotted lines in the figure. Apparent activation energies from these data were -490 and $-330 \mathrm{~J} / \mathrm{g}$ for G” and $\tan \delta$ peaks, respectively. The new FK lot \#1 (blue diamonds) gave slightly higher glass transition temperatures compared to previous lots, probably due to slightly higher CTFE content [1]. Similar results for the $\beta$-relaxation are shown in Figure 3. Lot numbers and color scheme are identical in both figures. The apparent activation energies $\left(E_{\text {act }}\right.$ ) of the $\beta$-relaxation frequency-dependence from peaks in the loss modulus and tan delta were -74 and $-56 \mathrm{~J} / \mathrm{mole}$, respectively. The variability from lot to lot at constant frequency of a $\beta$-relaxation peak was about $20^{\circ} \mathrm{C}$. The new FK lot \#1 (blue diamonds) gave similar $\beta$-relaxation peaks to the other lots. 


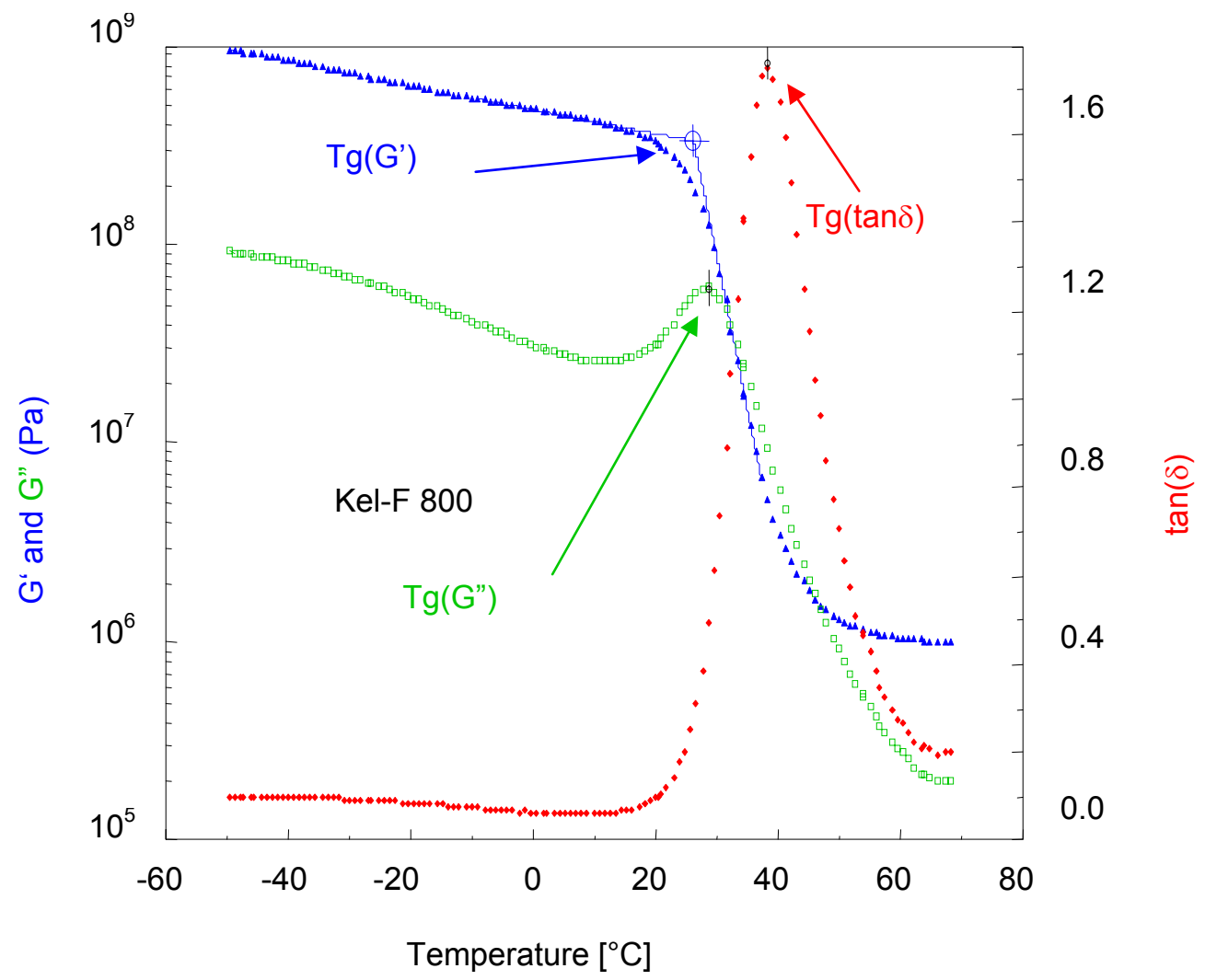

Figure 1. A $1 \mathrm{~Hz}$ DMA trace of Kel-F 800 shows a 3 order reduction in modulus through its glass transition temperature

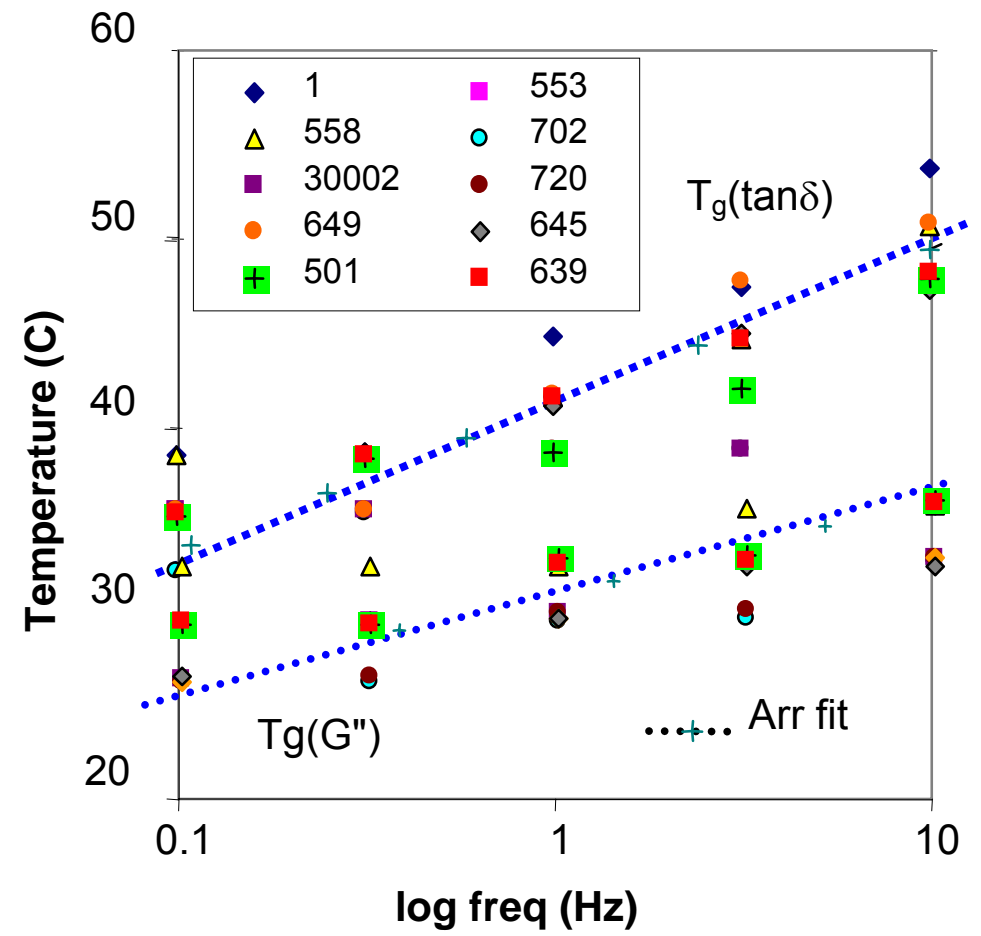

Figure 2. Frequency dependence of the glass transition temperature as measured by G” and tan delta peaks yield $E_{\text {act }}$ of -490 and $-330 \mathrm{~J} / \mathrm{mol}$, respectively. 


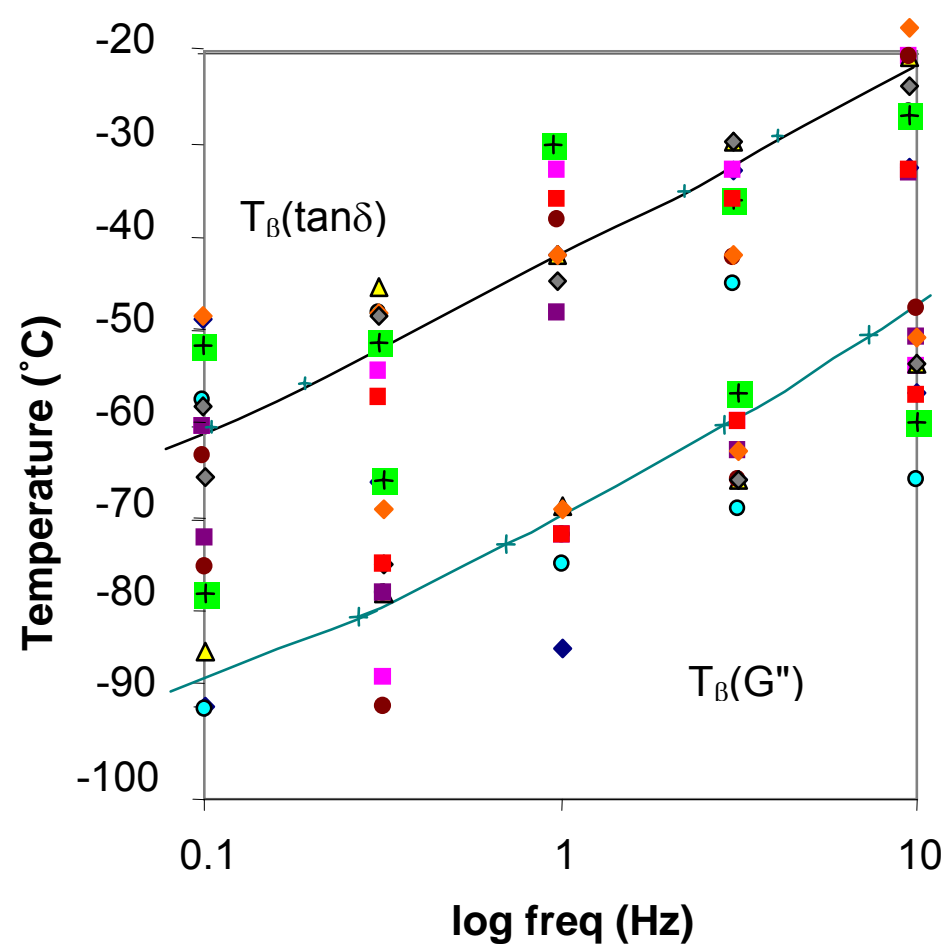

Figure 3. Temperature-frequency dependence of the low-temperature $\beta$-relaxation showed about $20^{\circ} \mathrm{C}$ scatter between various lots.

More sophisticated analysis can generate frequency dependences using the time temperature superposition principle. This principle allows data measured at one temperature at various frequencies to be shifted along the frequency axis to align with data measured at the same frequency, but at a reference temperature. We chose $32.8^{\circ} \mathrm{C}$ as the reference temperature and shifted data over the entire temperature range with respect to this temperature. The amount of shift along the frequency axes for lot 1 is plotted in Figure 4. As can be seen in the figure, there are two sections, a linear section associated with low temperature Arrhenius change in the modulus of the polymer and curved section as the glass transition is approached, associated with WLF behavior of the modulus near $\mathrm{T}_{\mathrm{g}}$. The result of applying the shift factor to the data is a modulus frequency master curve which is shown in Figure 5 for lot $\# 1$ at a reference temperature of $32.8^{\circ} \mathrm{C}$.

All 10 Kel-F 800 samples were shifted over the glass transition region and fitted to Arrhenius and WLF equations:

$$
\begin{array}{lll}
\text { Arrhenius: } & \ln \mathrm{aT}=\ln \mathrm{C}_{1}+\mathrm{E}_{\mathrm{act}} / \mathrm{R}\left(\mathrm{T}-\mathrm{T}_{\mathrm{ref}}\right) & 1 \\
\text { WLF: } & \log \mathrm{aT}=-\mathrm{c}_{1}\left(\mathrm{~T}-\mathrm{T}_{\mathrm{ref}}\right) /\left[\mathrm{c}_{2}+\mathrm{T}-\mathrm{T}_{\mathrm{ref}}\right] & 2
\end{array}
$$

Where $\mathrm{C}_{1}, \mathrm{c}_{1}$ and $\mathrm{c}_{2}$ are constants, $\mathrm{T}_{\text {ref }}$ is the reference temperature $\left(32.8^{\circ} \mathrm{C}\right), \mathrm{T}$ is the temperature of shifted data and aT is the horizontal shift factor for the property which is to be shifted. Usually G', G” and tan delta were all shifted, but occasionally better fits were obtained when only G' was shifted. The data was shifted over a temperature range 


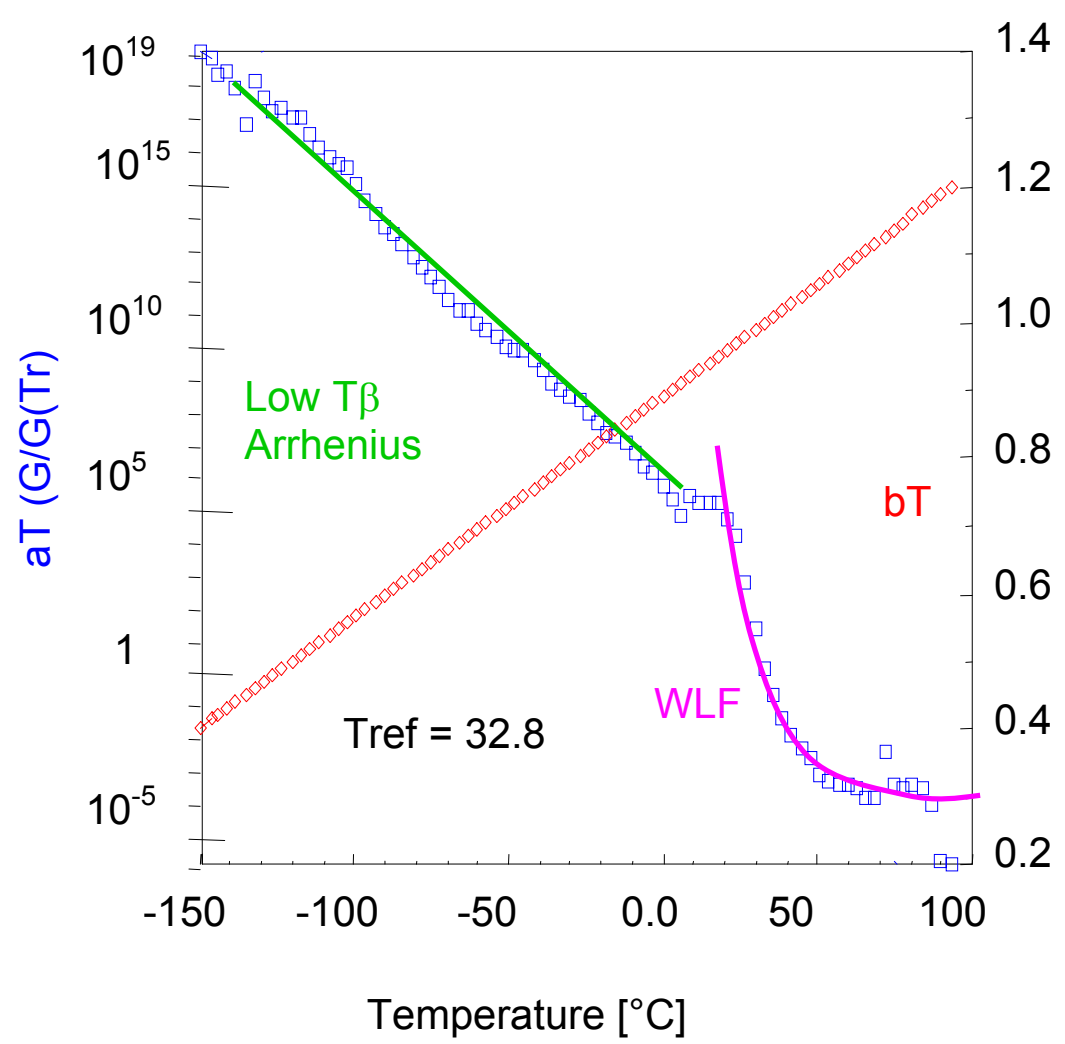

Figure 4. Time-temperature superposition shift factor for lot 1 showed 2 regions.

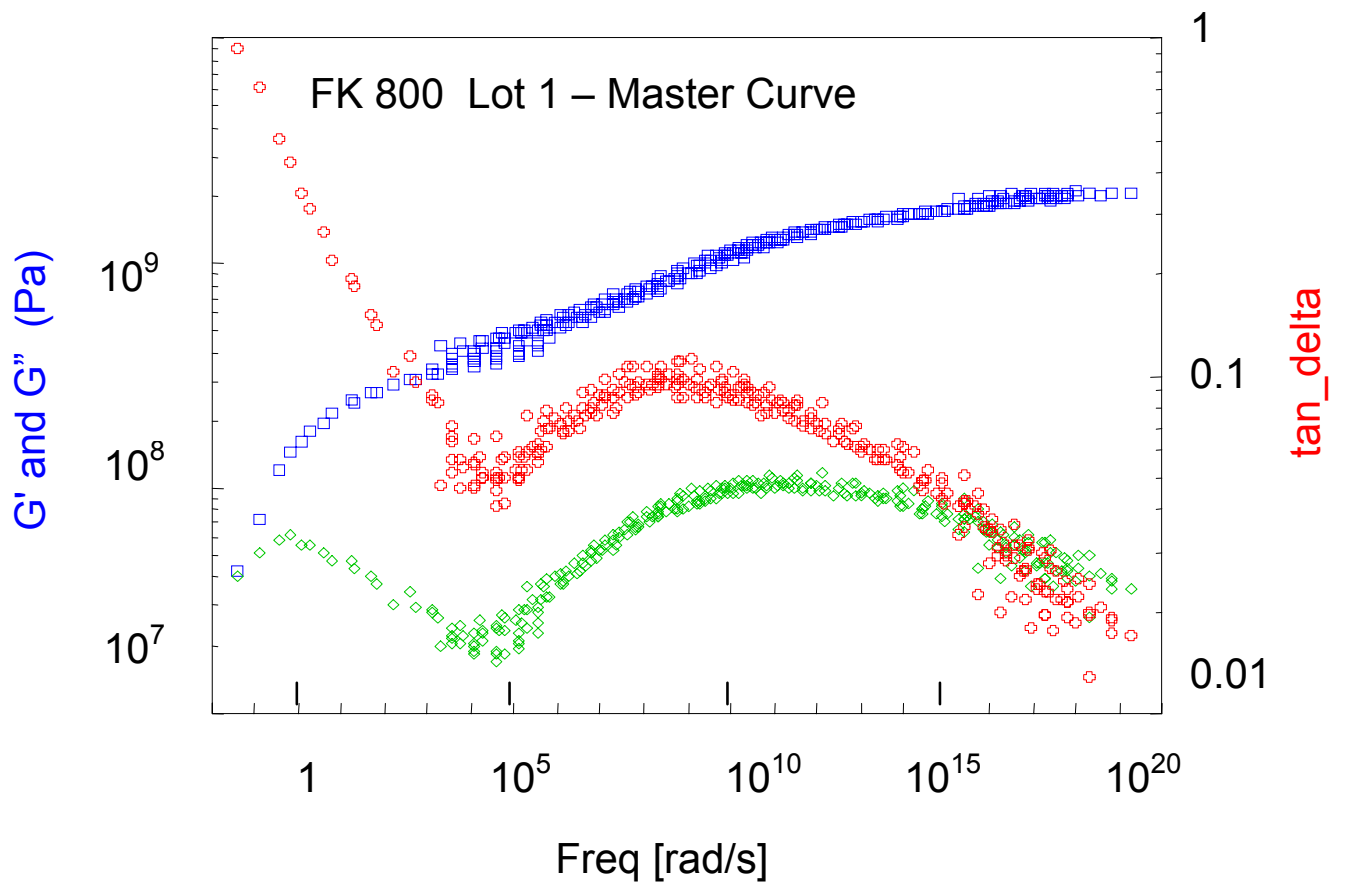

Figure 5. Shear modulus-frequency master curve for new FK 800 Lot \#1 at a reference temperature of $32.8^{\circ} \mathrm{C}$ shows the $\beta$-relation and glass transition as a function of frequency. 
from about 10 to $70^{\circ} \mathrm{C}$. Since these samples were freshly prepared, only very limited amounts of crystallinity had developed so above about $60^{\circ} \mathrm{C}$ the sample is very soft and data is not always good. Several reference temperatures were tried until the best correlation to the WLF fit was found. Then the $c_{1}$ and $c_{2}$ values were adjusted to the reference temperature of the WLF best fit for lot $1\left(32.8 \mathrm{C}^{\circ}\right)$ using:

$$
\mathrm{c}_{1}(\mathrm{~T})=\mathrm{c}_{1}\left(\mathrm{~T}_{\text {ref }}\right) * \mathrm{c}_{2}\left(\mathrm{~T}_{\text {ref }}\right) /\left[\mathrm{c}_{2}\left(\mathrm{~T}_{\text {ref }}\right)+\mathrm{T}-\mathrm{T}_{\text {ref }}\right] \quad 3
$$

and $\quad \mathrm{c}_{2}(\mathrm{~T})=\mathrm{c}_{2}\left(\mathrm{~T}_{\mathrm{ref}}\right)+\mathrm{T}-\mathrm{T}_{\mathrm{ref}}$

The results are given in Table 1 . As can be seen in the data, $c_{1}$ was averaged $9.17 \pm 3.8$ with most of the data between 6.8 and 7.6 and $c_{2}$ averaged $36.7 \pm 16.1$, with lots 553 and 702 being outliers. $E_{\text {act }}$ from the Arrhenius fits averaged about $-400 \mathrm{~J} / \mathrm{mole}$, in the middle of the $\tan \delta$ and G” peak verses frequency estimates from Figure 2.

Table 1. WLF and Arrhenius shift factor fits for 9 lots of older Kel-F 800 samples compared well to the new lot 1 sample for $\mathrm{T}_{\text {ref }}=32.8 \mathrm{C}$.

\begin{tabular}{c|ccccccc}
\hline Lot \# & $\boldsymbol{c}_{\boldsymbol{1}}$ & $\boldsymbol{c}_{\boldsymbol{2}}$ & $\boldsymbol{c c}$ & $\boldsymbol{E a c t}$ & $\boldsymbol{c c}$ & $\boldsymbol{T g}(\boldsymbol{d})$ & $\boldsymbol{T g}(\boldsymbol{G} \boldsymbol{)}$ \\
\hline 1 & 6.7843 & 26.662 & 0.940 & -392.7 & 0.919 & 44.9 & 32.8 \\
553 & 6.9357 & 27.756 & 0.9622 & -402.9 & 0.964 & -- & 32.9 \\
558 & 12.934 & 35.377 & 0.913 & -434.2 & 0.928 & 41.7 & 32.6 \\
501 & 6.8211 & 28.248 & 0.9621 & -438.55 & 0.9524 & 38.8 & 33.0 \\
639 & 7.3661 & 29.011 & 0.9702 & -407.56 & 0.9374 & 41.6 & 32.8 \\
649 & 7.5722 & 35.356 & 0.9308 & -396.0 & .9377 & 41.9 & 29.7 \\
645 & 8.0306 & 34.168 & 0.8579 & -381.5 & 0.9675 & 41.2 & 29.8 \\
702 & 18.433 & 80.866 & 0.8978 & -327.9 & 0.961 & 41.6 & 29.7 \\
720 & 6.922 & 29.361 & 0.9468 & -429.9 & 0.861 & 38.9 & 30.1 \\
30002 & 9.947 & 40.439 & 0.7229 & -398.1 & 0.965 & 38.7 & 30.1 \\
Average & $9.17 \pm 3.8$ & $36.7 \pm 16$ & & $-400 \pm 32$ & & $41.0 \pm 2$ & $31.4 \pm 1.4$ \\
\hline
\end{tabular}

B. The linear thermal expansion coefficient $\left(\alpha_{1}\right)$ for ten lots of Kel F-800 was measured from -150 to $20^{\circ} \mathrm{C}$, to remain below the glass transition temperature. Because of the softening of amorphous Kel-F 800 as $T_{g}$ is approached, even under a slight tensile load, the specimen does not maintain its shape. Figure 6 shows six of the ten lots of KelF plotted as incremental thermal expansion and strain versus temperature. The strain was calculated according to the equation below and fitted to a second order polynomial where $\Delta \mathrm{L}$ is the incremental change in length produced by an incremental change in temperature, $\mathrm{L}$ is the length at $\mathrm{T}, \mathrm{L}_{0}$ is the original length, and $\mathrm{k}_{2}, \mathrm{k}_{1}$, and $\mathrm{k}_{0}$ are the coefficients of the polynomial fit following the procedure of Maienschein. [12, 13]

$$
\Delta \mathrm{L} / \mathrm{L}=\left(\Delta \mathrm{L} / \mathrm{L}_{0}\right) /\left(1+\mathrm{DL} / \mathrm{L}_{0}\right)=\mathrm{k}_{2} \mathrm{~T}^{2}+\mathrm{k}_{1} \mathrm{~T}+\mathrm{k}_{0}
$$


The linear thermal expansion coefficient is given by:

$$
\alpha_{1}=(\Delta \mathrm{L} / \mathrm{L}) / \Delta \mathrm{T}=2 \mathrm{k}_{2} \mathrm{~T}+\mathrm{k}_{1}
$$

Since $\alpha_{1}$ is also calculated directly during each incremental temperature change, we can fit its temperature dependence below $\mathrm{T}_{\mathrm{g}}$ by a straight line:

$$
\alpha_{1}=m T+b \text { where } m=2 * k_{2} \text { and } b=k_{1}
$$

For all lots: $\alpha_{1} \sim(44 * \mathrm{~T}+108) * 10^{-6}$ and $\Delta \mathrm{L} / \mathrm{L} \sim 2.2 * 10^{-7} * \mathrm{~T}^{2}+1.07 * 10^{-4} * \mathrm{~T}+0.011$. There was always a slight discrepancy between the temperature coefficient from the linear fit of $\alpha_{1}$ and the derivative of the $\Delta \mathrm{L} / \mathrm{L}$ polynomial. From equation $7, \mathrm{k}_{2} / \mathrm{m}$ should be 2 and the average of the $10 \mathrm{Kel} \mathrm{F}$ samples was $1.8 \pm 0.1$. Table 2 lists the coefficients for equations 5 and 6 for all 10 lots which were tested. As can be seen from Table 2 and Figure 1, the values are quite similar.

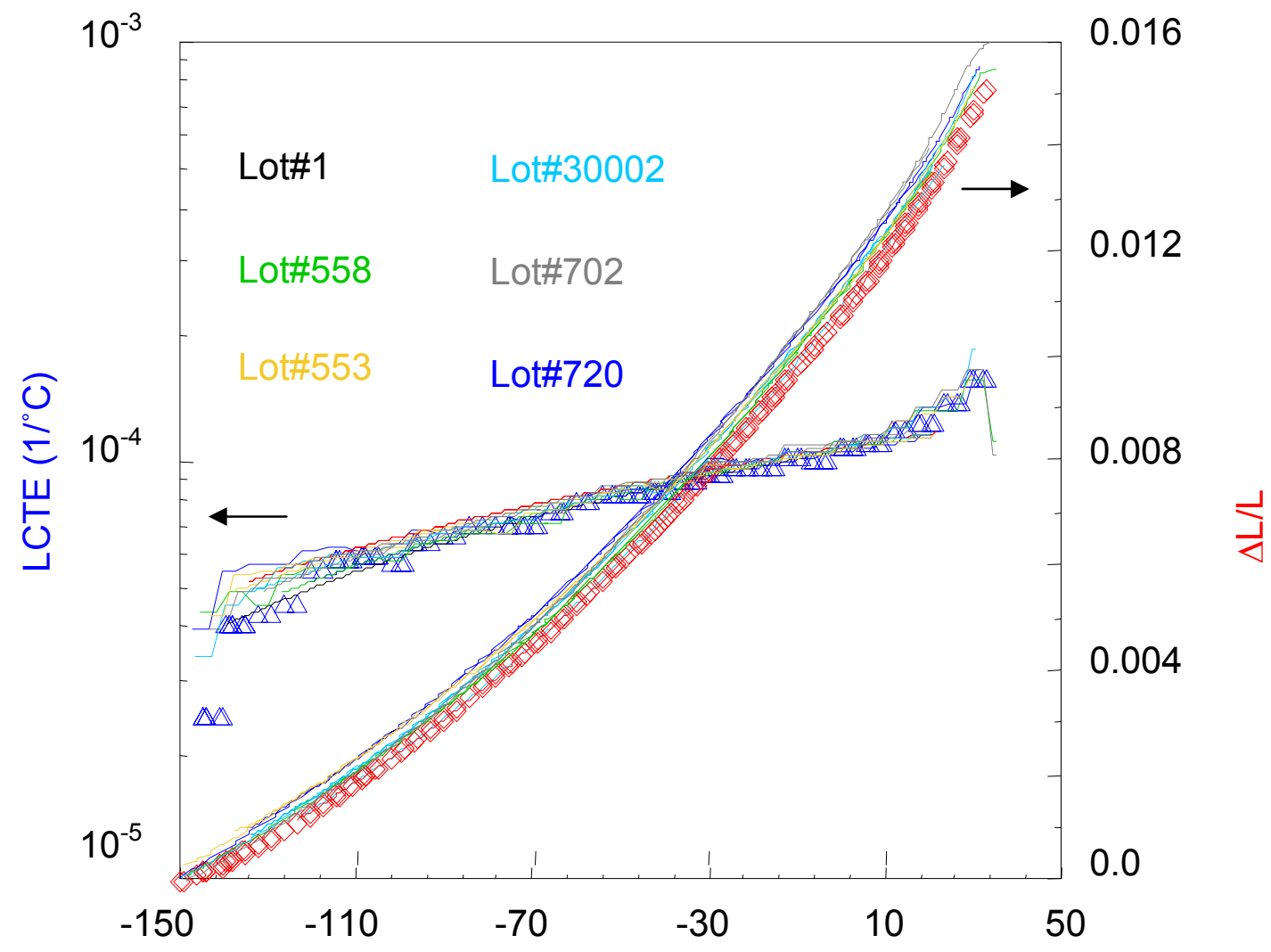

Temperature $\left[{ }^{\circ} \mathrm{C}\right]$

Figure 6. The linear thermal expansion coefficient $\left(\alpha_{1}\right)$ and dimensionless strain $(\Delta \mathrm{L} / \mathrm{L})$ of 9 lots of Kel-F 800 (only 6 lots shown) were very similar to the new FK 800 copolymer. 
Table 2. Temperature dependence of the linear thermal expansion coefficient of 10 lots of Kel-F 800 were very similar based on direct $\alpha_{1}$ and indirect $\Delta \mathrm{L} / \mathrm{L}$ measurements.

\begin{tabular}{ccccccc}
\hline $\boldsymbol{L o t} \#$ & $\boldsymbol{m}$ & $\boldsymbol{b}$ & $\boldsymbol{c c}$ & $\boldsymbol{2}^{*} \boldsymbol{k}_{\boldsymbol{2}}$ & $\boldsymbol{K}_{\boldsymbol{1}}$ & $\boldsymbol{c c}$ \\
\hline 1 & $4.40 \mathrm{E}-07$ & $1.04 \mathrm{E}-04$ & 0.9788 & $4.62 \mathrm{E}-07$ & $1.07 \mathrm{E}-04$ & 0.9999 \\
553 & $4.22 \mathrm{E}-07$ & $1.06 \mathrm{E}-04$ & 0.9595 & $4.56 \mathrm{E}-07$ & $1.09 \mathrm{E}-04$ & 0.9998 \\
558 & $4.57 \mathrm{E}-07$ & $1.06 \mathrm{E}-04$ & 0.9694 & $5.11 \mathrm{E}-07$ & $1.10 \mathrm{E}-04$ & 0.9999 \\
501 & $4.51 \mathrm{E}-07$ & $1.11 \mathrm{E}-04$ & 0.9369 & $5.50 \mathrm{E}-07$ & $1.20 \mathrm{E}-04$ & 1.000 \\
639 & $5.18 \mathrm{E}-07$ & $1.21 \mathrm{E}-04$ & 0.9759 & $6.20 \mathrm{E}-07$ & $1.31 \mathrm{E}-04$ & 1.000 \\
649 & $5.00 \mathrm{E}-07$ & $1.20 \mathrm{E}-04$ & .9783 & $5.88 \mathrm{E}-07$ & $1.29 \mathrm{E}-04$ & 0.9999 \\
645 & $5.93 \mathrm{E}-07$ & $1.22 \mathrm{E}-04$ & 0.9874 & $6.62 \mathrm{E}-07$ & $1.31 \mathrm{E}-04$ & 0.9999 \\
702 & $4.57 \mathrm{E}-07$ & $1.10 \mathrm{E}-04$ & 0.9775 & $4.80 \mathrm{E}-07$ & $1.12 \mathrm{E}-04$ & 0.9999 \\
720 & $4.25 \mathrm{E}-07$ & $1.08 \mathrm{E}-04$ & 0.9566 & $4.56 \mathrm{E}-07$ & $1.10 \mathrm{E}-04$ & 0.9999 \\
30002 & $4.44 \mathrm{E}-07$ & $1.07 \mathrm{E}-04$ & 0.967 & $4.62 \mathrm{E}-07$ & $1.09 \mathrm{E}-04$ & 0.9999 \\
\hline
\end{tabular}

3. Dynamic viscosity measurements were made as a possible replacement methodology for the "Zahn Cup" solution viscosity measurements called out in the specification of Kel-F 800. Parallel plate measurements on approximately $2 \mathrm{~mm}$ thick disks were made over the temperature range starting at 120 to $40^{\circ} \mathrm{C}$. Figure 7 shows the results for Lot \#1. Two separate samples were run from this lot and the data compared to

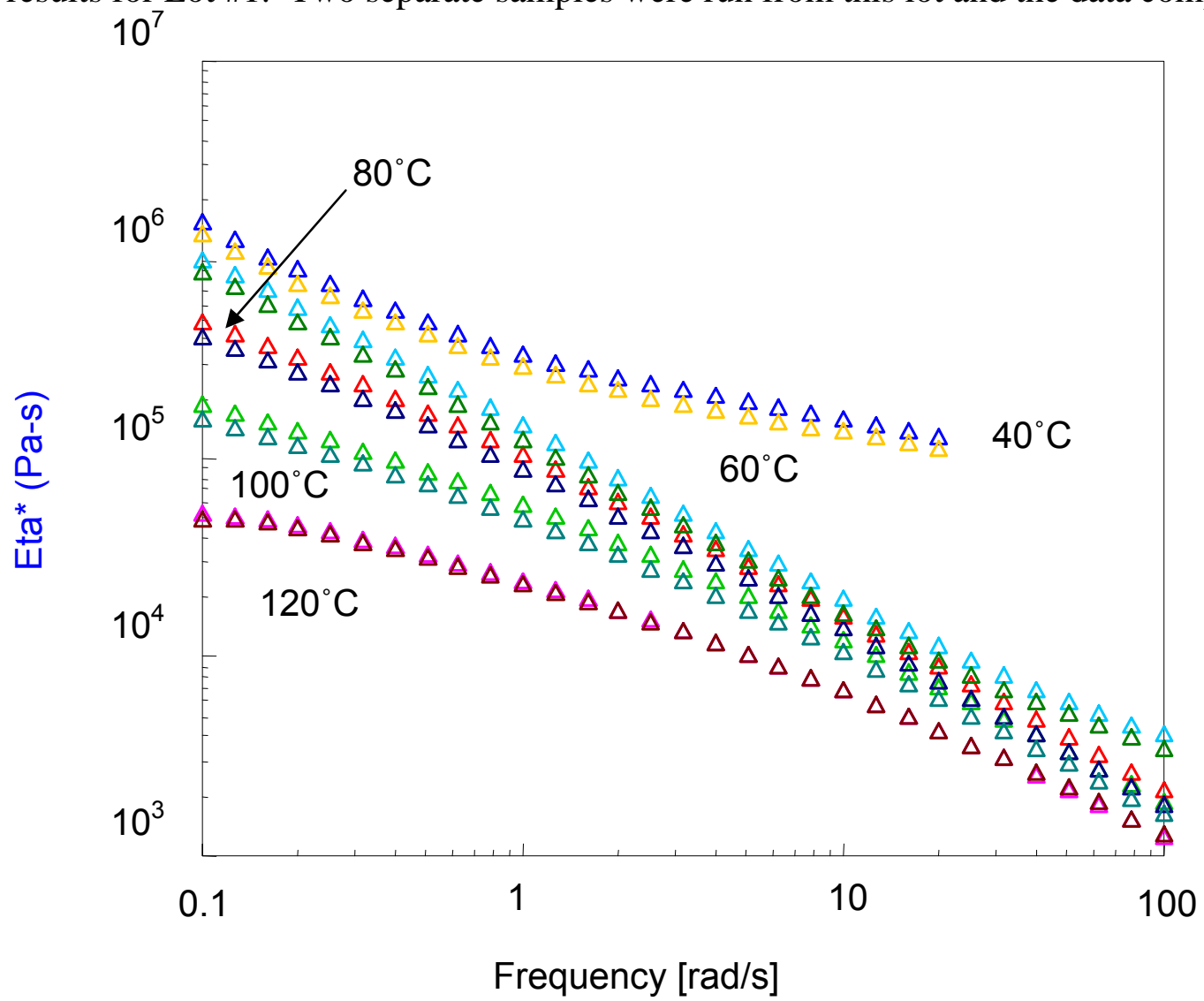

Figure 7. Dynamic viscosities of two disks of FK 800 from lot 1 measured from 0.1 to $100 \mathrm{rad} / \mathrm{s}$ at 5 temperatures between 120 and $40^{\circ} \mathrm{C}$ showed reasonable reproducibility. 
give some idea of the reproducibility of the measurements within a given lot. Typical shear thinning behavior for moderate molecular weight polymers is observed, with a limiting viscosity at lower frequencies and shear rates. As can be seen in the figure, the $40^{\circ} \mathrm{C}$ run deviates from shear thinning behavior, due to the approaching glass transition temperature and its frequency dependence, and also possibly due to some crystallization under shear. The zero shear rate limiting viscosities begin to be seen at $0.1 \mathrm{rad} / \mathrm{s}$ at about $80^{\circ} \mathrm{C}$. Zero shear viscosity could provide a number to replace the specification Zahn cup measurement. At temperatures $100^{\circ} \mathrm{C}$ above $\mathrm{T}_{\mathrm{g}}$, an Arrhenius viscosity is usually seen for zero shear viscosities, where $\mathrm{E}_{\text {flow }}$ is the apparent flow activation energy:

$$
\eta_{0}(\mathrm{~T})=\mathrm{A} \exp \left(-\mathrm{E}_{\text {flow }} / \mathrm{RT}\right)
$$

The $0.1 \mathrm{rad} / \mathrm{s}$ dynamic viscosity from all lots at 5 temperatures is compared in Table 3. This approximation for zero shear viscosity was used to estimate the apparent flow activation energy from Equation 8. Figure 8 shows the results are not linear.

\begin{tabular}{|c|c|c|c|c|c|c|}
\hline Lot \# & $\eta_{0}^{*}(40)$ & $\eta_{0}^{*}(60)$ & $\eta_{0}^{*}(80)$ & $\eta_{0}^{*}(100)$ & $\eta_{0}^{*}(120)$ & $\eta_{0 \xi}(120)$ \\
\hline 1 & 15.1 & 9.95 & 4.83 & 1.85 & 0.516 & 0.69 \\
\hline 1 (2nd) & 13.3 & 8.65 & 4.13 & 1.56 & 0.493 & 0.667 \\
\hline 553 & 32.8 & 20.1 & 7.65 & 2.3 & .586 & 0.712 \\
\hline 558 & 19.3 & 14.2 & 8.71 & 3.87 & 1.47 & 2.06 \\
\hline 501 & & & & & & \\
\hline 639 & 14.0 & 10.6 & 6.46 & 3.14 & 1.37 & 2.05 \\
\hline 649 & 22.2 & 16.2 & 8.80 & 3.80 & 1.25 & 1.37 \\
\hline 645 & 18.3 & 13.3 & 6.94 & 2.89 & 0.978 & 1.88 \\
\hline 702 & 15.8 & 12.4 & 7.76 & 3.97 & 1.22 & 1.90 \\
\hline 720 & 16.0 & 12.3 & 8.50 & 4.33 & 1.75 & 2.69 \\
\hline 30002 & 8.14 & 6.41 & 4.72 & 2.73 & 1.05 & 1.68 \\
\hline
\end{tabular}

Units are MPa-s.

The Ellis model has been used for describing fluids which show Newtonian behavior at low shear rates, shear thinning behavior at higher shear rates with intermediate behavior between these limits. The Ellis model has 3 constants $\eta_{0}, \kappa_{1}$, and $\kappa_{2}$, where $\eta_{0 \xi}$ is the zero shear viscosity of the model, $\kappa_{1}$, is related to the intermediate behavior and $\kappa_{2}$, produces the steady state slope of the shear thinning, high shear rate behavior. The model takes the form:

$$
\eta(\omega)=\eta_{0 \xi} /\left[1+\left(\omega / \kappa_{1}\right)\right]^{\kappa 2-1}
$$

Figure 10 plots the dynamic viscosities of the different lots of Kel-F 800 at $120^{\circ} \mathrm{C}$. The Ellis model was fitted to each data set and the average of each coefficient was used to generate the curve shown in the figure. Table 4 gives the coefficients for the model. The initial viscosity coefficient $\left(\eta_{0 \xi}\right)$ varies in the same manner as the $0.1 \mathrm{rad} / \mathrm{s}$ viscosity, ie, the newer polymers had lower $\eta_{0 \xi}, 0.6 \mathrm{MPa}$-s for lot 1 compared to $2.67 \mathrm{MPa}$-s for lot 
720. The intermediate region constant $\left(\kappa_{1}\right)$ varied between $0.15-0.85$ averaging about $0.34 \pm 0.2$. The most extreme intermediate range was lot 553 . The shear thinning region $\left(\kappa_{2}\right)$ averaged about $1.57 \pm 0.06$ with the outliers being lot 553 (1.67) on the low end and lot 30002 (1.85) being the most shear thinning. It might be interesting to see how the low shear viscosities affect pressing densities of LX-17.

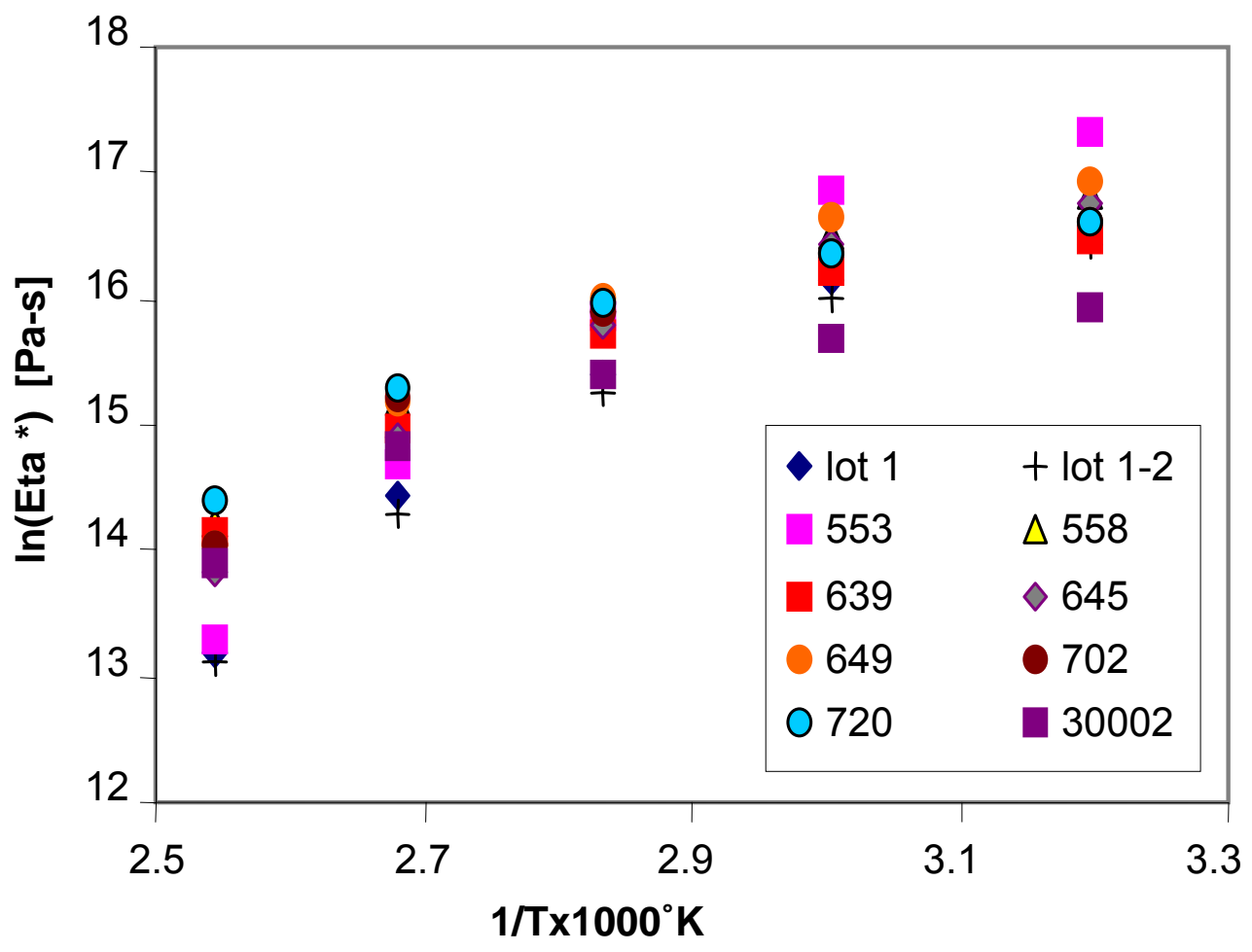

Figure 9. Attempts to determine the flow activation energy show curvature in the low temperature data.

Table 5. Coefficients of the Ellis model for various lots of Kel-F 800

\begin{tabular}{c|ccccc}
\hline lot & $\eta_{0 \xi}(\mathrm{Pa}-\mathrm{s})$ & $\kappa_{1}$ & $\kappa_{2}$ & corr & var \\
\hline 1 run 2 & $6.90 \mathrm{E}+05$ & 0.45734 & 1.73139 & 0.9991 & $5.50 \mathrm{E}-04$ \\
1 & $6.67 \mathrm{E}+05$ & 0.45589 & 1.72164 & 0.9989 & $6.31 \mathrm{E}-04$ \\
553 & $7.12 \mathrm{E}+05$ & 0.89761 & 1.67285 & 0.9994 & $3.28 \mathrm{E}-04$ \\
558 & $2.06 \mathrm{E}+06$ & 0.24579 & 1.76118 & 0.9981 & $1.00 \mathrm{E}-03$ \\
639 & $2.05 \mathrm{E}+06$ & 0.1988 & 1.7777 & 0.9986 & $8.60 \mathrm{E}-04$ \\
645 & $1.37 \mathrm{E}+06$ & 0.30518 & 1.73159 & 0.9988 & $7.36 \mathrm{E}-04$ \\
649 & $1.88 \mathrm{E}+06$ & 0.23743 & 1.73656 & 0.9989 & $7.04 \mathrm{E}-04$ \\
702 & $1.90 \mathrm{E}+06$ & 0.23598 & 1.81317 & 0.9992 & $5.34 \mathrm{E}-04$ \\
720 & $2.69 \mathrm{E}+06$ & 0.17084 & 1.8336 & 0.9977 & $1.70 \mathrm{E}-03$ \\
30002 & $1.68 \mathrm{E}+06$ & 0.14756 & 1.85201 & 0.9978 & $1.90 \mathrm{E}-03$ \\
Average & $1.57 \pm 0.7$ & $0.33 \pm 0.2$ & $1.76 \pm 0.07$ & & \\
\hline \multicolumn{7}{r}{}
\end{tabular}




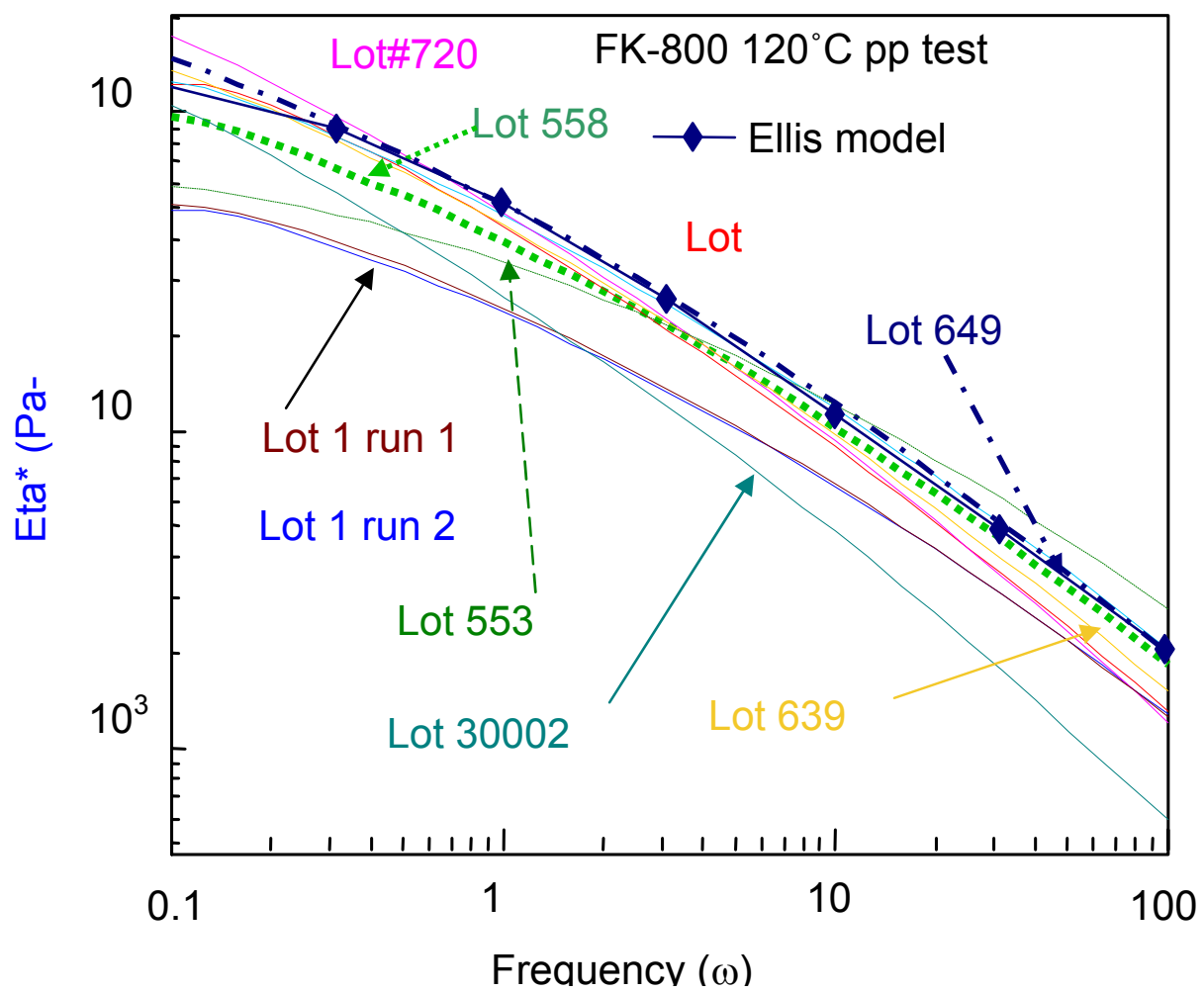

Figure 10. Dynamic viscosities of lots of Kel-F 800 and the average coefficients fit to the Ellis Model (Eqn. 9) show that 558, 600, and 700 lots have higher viscosities and steeper shear thinning than lot 1 at $120^{\circ} \mathrm{C}$.

4. The Plateau modulus is related to the entanglement length of a polymer chain $\left(\mathrm{M}_{\mathrm{c}}\right)$. As the molecular weight of a polymer increases it becomes more and more viscous because of the higher number of transient crosslinks caused by the molecules being entangled. The plateau modulus $\left(\mathrm{G}_{\mathrm{n}}{ }^{0}\right)$, the flat portion of the $\mathrm{G}^{\prime}$ trace above the glass transition temperature is related to the entanglement length by:

$$
\mathrm{G}_{\mathrm{n}}^{0}=(4 / 5) \rho \mathrm{RT} / \mathrm{M}_{\mathrm{c}}
$$

10.

where $\rho$ is the density. The five data sets obtained from the dynamic viscosity measurements above were evaluated for each lot of Kel-F 800. The data were shifted using a two dimensional shift factor for the high temperature parallel plate measurements. The plateau can be estimated in a variety of ways $[14,15]$. The shear storage modulus value above the glass transition at the minimum in the loss modulus was chosen for simplicity. Theoretical tube models are not usually applied to polydisperse polymers, so more complex estimates were not performed. Figure 11 compares the results for 5 lots of Kel F-800. As can be seen in the figure, these lots are fairly similar with the plateau modulus varying around 1.6 to $2.8 \mathrm{MPa}$. This yields an entanglement molecular weight from Eqn. 10 of between 140,000 - 78,000 for newer lots and as low as 31,6000 - 52,000 for older lots. If the molecular weight distribution for each lot is known an estimate of the number of entanglements $(\zeta)$ can be made from $\zeta=\mathrm{M}_{\mathrm{w}} / \mathrm{M}_{\mathrm{e}}$. Unfortunately most of the lots which were available had no molecular weight distributions. Pantex has kindly agreed to measure these samples for us. Based on 3M's styrene equivalent molecular 
weights $\mathrm{z}$ for lot 1 was 1.18 and 1.34 for lot 720 . Table 12 gives the plateau modulus and entanglement molecular weights for the lots which have been measured to date.

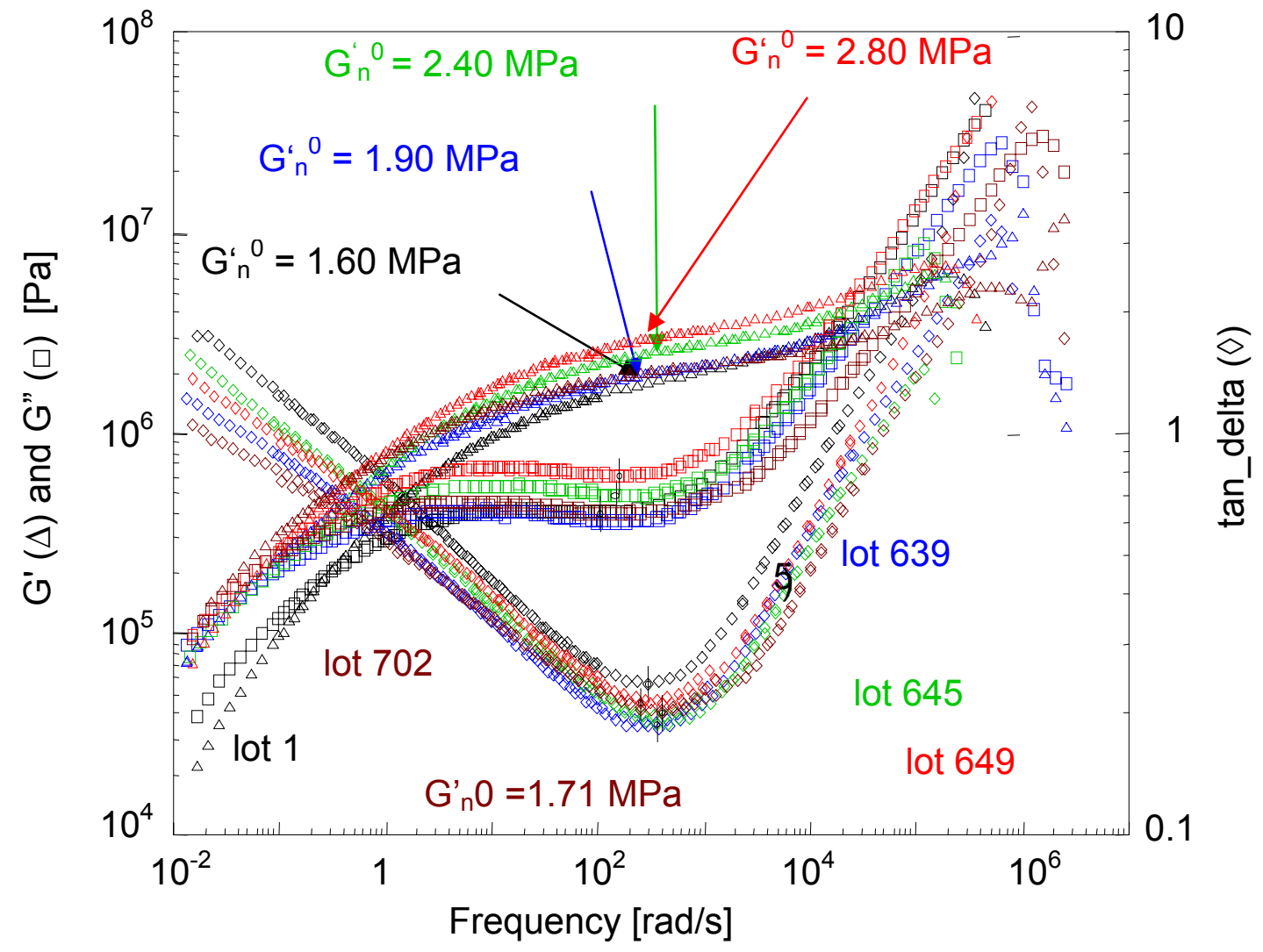

Figure 11. The plateau modulus can be estimated from the shear storage modulus value above the glass transition at the minimum in the loss modulus. Five lots of Kel-F 800 are shown. $\mathrm{T}_{\text {ref }}=100^{\circ} \mathrm{C}$

Table 1. Plateau modulus, molecular weight data where available, entanglement molecular weight and number of entanglements are given for 10 lots of Kel-F 800.

\begin{tabular}{c|ccccccc}
\hline & $M n$ & $M w$ & $M n$ & $M w$ & $P M$ & $M e$ & $\zeta$ \\
\hline Lot & $\mathrm{kDa}$ & $\mathrm{kDa}$ & $\mathrm{kDa}$ & $\mathrm{kDa}$ & $\mathrm{MPa}$ & $\mathrm{kDa}$ & \\
1 & 43.4 & $92.4^{*}$ & 41.7 & $93.8^{*}$ & 1.59 & 78.0 & 1.18 \\
501 & & & & & & & \\
553 & & & & & 3.92 & 31.6 & \\
558 & & & & & 2.44 & 50.9 & \\
639 & 15.9 & 46.5 & 37.1 & 64.1 & 1.90 & 65.3 & 0.71 \\
645 & & & & & 2.40 & 51.6 & \\
649 & & & & & 2.81 & 44.2 & \\
702 & & & & & 1.71 & 72.7 & \\
720 & & & 44.3 & $99.7^{*}$ & 1.66 & 74.7 & 1.34 \\
3002 & & & & & 0.89 & 139.3 & \\
\hline
\end{tabular}

Molecular weights are color coded according to who made the measurement: red = 3M; green = AWE, magenta $=\mathrm{LLNL}$, Blue $=\mathrm{U}$ of Alabama. $*$ indicates polystyrene equivalent molecular weights were reported. 
Task 2. Characterization of new TATB.

We have begun evaluation the morphology TATB synthesized by BAE Holston and ATK Thiokol and comparing them with wet aminated (WA) TATB which is no longer manufactured in the US. Optical and SEM micrographs have been made and pressing characteristics of the dry powder as a function of pressure were performed and will be described in the next quarterly. Small scale safety data on these TATBs are in the works. We plan to attempt to determine the density distributions of these TATB crystals using a gradient column approach and compare them to WA TATB.

Task 3. Formulate LX-17-2, -3 using new TATB and new FK 800 lot 1 . We are in the process of setting up our $50 \mathrm{~g}$ slurry coater and formulate LX-17-2 and -3 with BAE and ATK TATB, compression mold the resulting samples and measure mechanical properties.

\section{Conclusions:}

Rheological and dynamic mechanical measurements of 10 lots of Kel-F 800 polymer showed some variability between lot to lot. Dynamic mechanical and thermal expansion behavior below the glass transition temperature was very similar. The glass transition for the newer FK 800 polymer was slightly higher than many older lots, probably due to the higher CTFE content. The rheological properties of older lots tended to be different than newer lots. This may be due to aging or some difference associated with the change in polymerization procedures. Typically, newer lots had lower zero shear viscosity and weaker shear thinning behavior. This could be seen in the coefficients of the Ellis model. Newer lots had lower plateau moduli also. Assuming tube model behavior for the entanglement relaxation, this could imply some branching in the older polymers, though the similarity of these curves, suggests that it is very small. It would appear that the new lot 1 polymer is sufficiently similar that it would not adversely effect the PBXing process for LX-17. The proof of the pudding will, of course, be formulation with this polymer, which is planned in the next few months.

\section{Acknowledgements:}

Special thanks to Al Shields who ran the rheological measurements.

\section{Reference:}

1. A. Manzara, "New Production of KF-800, and Characterization of Differences" Unpublished Results, 3M Specialty Materials Division (2006).

2. A Manzara, "New Production of K F-800, and Characterization of Differences" 3M Specialty Materials Division, Presented at LANL Energetic Materials Review, Oct 2-5, 2006.

3. J.C. Colville, "LX-17 and LX-10 Test Data” SR-92-03 (June 9, 1992) Pantex Plant. 4. B. Sleadd, "Synthesis and Scale-up of sym-triaminotrinitrobenzene at Holston Army Ammunition Plant, 2006 IM\&EM Technology Symposium, Bristol, UK. 
5. S. Velarde, "Pilot Plant Synthesis of Triaminotrinitrobenzene (TATB)" 2006 IM\&EM Technology Symposium, Bristol, UK.

6. T. Mahoney, private communication (2006)

7. D. Battelbaum, S. Sheffield, D. Robbins, P.J. Rae, E.N. Brown, and E.B. Orler, "Recent Experimental Progress: Polymers under Dynamic Loading", Presented at Mach I/3m KF-800 Meeting, 3M Center, October 17, 2006.

8. B. Russell, Pantex, private communication at the 3M/Mach 1 KF-800 symposium, October 17, 2006.

9. L. Byers and P. Deacon, “Characterisation of KF-800 Lot 1", Presented at Mach I/3m KF-800 Meeting, 3M Center, October 17, 2006.

10. A. Dunsten, "Summary of Kel-F 800 and FK-800 analysis for AWE” Unpublished results, AWE, Aldermaston UK (200

11. "Materials Specification For Kel-F 800” 13Y-188481, Los Alamos Scientific Laboratory (1978)

12. J.L. Maienschein and F. Garcia, "Thermal expansion of TATB-based explosives

from 300 to $566 \mathrm{~K}$ ” Thermochimica Acta 384 (2002) 71-83.

13. B. J. Cunningham, T. Tran, R. Weese, P. Lewis, P. Harwood and T. Healy, unpublished results (May 27, 2003).

14. J.D. Ferry, Viscoelastic Properties of Polymers. 3rd ed. New York: Wiley; 1980.

15. C. Liu, J. He, E. van Ruymbeke, R. Keunings and C. Bailly, "Evaluation of different methods for the determination of the plateau modulus and the entanglement molecular weight, Polym. 47 (2006) 4461-4479. 